\title{
An Empirical Analysis of the Efficiency of My Country's Private Investment Structure
}

\author{
Sun $\operatorname{Min}^{1, a^{*}}$ \\ ${ }^{1}$ School of Economics and Management of XI'an Mingde Institute of Technology, Xi'an, Shaanxi, China \\ $a^{*} 33744205 @ q q . c o m$
}

\begin{abstract}
Affected by the weakening of the global economy, the role of export trade in promoting my country's economic growth has gradually weakened. In addition, measures to stimulate economic growth by domestic demand are difficult to achieve in the short term. Investment, as one of the "troikas" of my country's economic development, has been placed more importantly. With the development of the economy, private investment has developed rapidly and its scale has continued to grow. It has replaced state-owned investment as the main force in my country's fixed asset investment. Although private investment has achieved tremendous growth in quantity, the long-term economic development in the future will not only depend on private investment. The improvement of the efficiency of private investment is more important.

Therefore, this article uses quantitative and qualitative analysis, comparative analysis and other methods, starting from the actual situation of the efficiency of China's private investment structure, and empirically analyzes the efficiency of my country's private investment structure, and concludes that the industry structure efficiency of my country's private investment is generally low. The conclusion of the unbalanced development of structural efficiency. Therefore, the key to improving the industrial structure efficiency of private investment is technical efficiency.
\end{abstract}

Keywords: Private investment, Structure, Efficiency

\section{我国民间投资结构效率实证分析}

\author{
孙敏 $1, \mathrm{a}^{*}$ \\ 1 西安明德理工学院经济与管理学院, 西安, 陕西, 中国 \\ a*33744205@qq.com \\ 摘要:受全球经济疲软的影响, 出口贸易对我国经济增长的推动作用逐渐减弱, 加之内需拉动经济增长的措施 \\ 在短期内难以实现，投资作为我国经济发展的“三驾马车”之一被摆在了更为突出的地位。随着经济的发展， \\ 民间投资发展迅速，规模不断增长，已经取代国有投资成为我国固定资产投资的主力军，虽然民间投资在数 \\ 量上取得了巨大发展, 但是未来经济的长期发展不仅依赖于民间投资数量的增加, 更重要的是民间投资效率 \\ 的提高。 \\ 因此，本文运用定量与定性分析、比较分析等方法，从我国民间投资结构效率的实际情况出发，对我国民间 \\ 投资结构效率进行实证分析, 得出我我国民间投资的行业结构效率普遍较低, 地区结构效率发展不平衡的结 \\ 论。因此，提高民间投资的行业结构效率的关键是技术效率。
}

关键词：民间投资；结构；效率

\section{1.研究背景}

根据最新的 2020 年《中国统计年鉴》的统计数 字，2019 年我国全社会固定资产投资总额为 560874 亿元, 其中, 民间投资总额是 311159 亿元, 占到全
社会固定资产投资总额的 $55.48 \%$ ，这充分表明民间 投资已经取代国有投资成为了我国固定资产投资的 主力。

虽然我国民间投资已经取得了数量上的巨大发 
展，但是其投资效率仍然存在一些问题。目前我国民 间投资的投资效率依然处于较低的水平，投资的增长 主要依赖的还是要素投入, 盲目的、低水平的重复建 设导致了无效的资金占用、产品积压等问题，从而造 成严重的资源浪费。投资需求虽然得到了扩大，但是 并未形成有效的供给, 最终造成全社会总需求与总供 给的严重失衡以及产业结构的严重扭曲。因此，民间 投资的效率问题是关乎我国经济健康发展以及产业 结构优化升级的大问题。

\section{2.民间投资结构效率评价的理论基础}

帕累托最优理论是民间投资结构效率的理论依 据。在一个经济体中, 资源是稀缺的, 但是它具有流 动性, 其流动方向是从边际生产率低的部门或地区流 向边际生产率高的部门或地区, 这种流动性可以实现 不同部门或地区之间资本产出率的均等化, 从而最终 实现全社会的福利最大化，对于民间投资而言，当民 间投资中各部门或地区实现了各投入要素边际转换 率的均等化时, 那么这些部门或地区的民间投资产出 便都能达到帕累托最优状态，此时，民间投资资本在 各个部门或地区实现了资源的最优化配置, 即实现了 民间投资的结构效率。因此，民间投资的结构效率也 就是使得民间投资的各个部门或地区都实现最大化 产出时的民间投资资源配置。

\section{3. 民间投资结构效率测度方法}

本文对民间投资结构效率的研究采用数据包络 分析方法(Data Envelopment Analysis，简记 DEA), DEA 方法是数学、运筹学、数理经济学和管理科学的 一个新的交叉领域（盛昭瀚，1996）。该方法是由美 国著名的运筹学家 A.chames 和 W.W.cooper (1978) 等在“相对效率评价”概念基础上发展起来的一种全 新的效率评价方法, 由于 DEA 方法具有无须设置权 重、无须对指标值无量纲化处理、无须设置特定的函 数形式、具有较高的灵敏度与可靠性以及为改进评价 目标提供建议等优点, 因而该方法自诞生以来就受到 人们的关注, 不论在理研究还是在实际应用方面都得 到迅速发展。在具体的实证分析中, 本文采用非阿基 米德无穷小量 $\varepsilon$ 的 $\mathrm{C} 2 \mathrm{R}$ 模型分析民间投资的行业结 构效率，使用 Malmquist DEA 法分析民间投资的地区 结构效率。

\section{4. 民间投资结构效率的实证分析}

使用 DEA 模型分析我国民间投资行业部门的结 构效率，得到的是民间投资行业部门结构的相对效率， 是比较分析民间投资行业部门在相应考察年度的相 对结构效率。鉴于数据的可得性，本文分析民间投资 行业结构效率的时间段是 2012-2019 年，民间投资数 据则是分配到各个行业部门的民间投资数量, 即行业 固定资产投资减去行业国有、港澳台和外商投资的剩 余部分。

\section{1. 非阿基米德无穷小量 $\varepsilon$ 的 $C 2 R$ 模型分析}

\subsection{1. 基本模型的建立}

2012 年-2019 年共包括 8 个年度, 因此决策单元 DMU 有 8 个。对于样本, 输入变量 X1-X9 分别选择 农林牧渔业, 采矿业, 制造业, 电力、燃气及水的生 产和供应业, 交通运输、仓储和邮政业, 批发和零售 业, 房地产业, 水利、环境和公共设施管理业以及其 他行业这 9 个行业的民间现为拉动投资, 扩大内需从 而促进宏观经济发展, 那么输出变量我们可以选择 GDP 增长率(Y1)、城镇居民人均可支配收入增长率 （Y2）（由于民间投资的行业数据仅是城镇数据, 不包 含农户，因而输出变量只选择城镇居民人均收入和人 均支出）、城镇居民人均生活消费支出增长率(Y3)、 就业人员增长率 $(\mathrm{Y} 4)$ 以及全社会固定资产投资总额 增长率 $(\mathrm{Y} 5)$ (单位均为 \%)。

\subsection{2. 模型求解及分析}

将上述输入和输出变量代入 DEA 模型中, 可以 计算出我国民间投资行业部门结构 2012-2019 年的效 率值 $\theta^{*} 、 s^{*} 、 s^{*}$ 具体结果如表 1 所示。从分析 结果可以看出, 2012-2019 年每年的 $\theta^{*}=1$ 且 $\bar{s} *$ $S^{*}=0$, 根据 DEA 模型的有效性理论可以得出 2012 年-2019 年这八年的 DMU 都是 DEA 有效的, 即这八 年中我国民间投资行业部门结构处于相对效率之中， 意味着投向每个行业的民间资本基本上实现了其投 资价值，为国民经济的增长、人民生活水平的提高以 及就业的增加起到了一定的作用。

表 1 2012-2019 年我国民间投资行业部门结构效率 DEA 分析结果

\begin{tabular}{l|c|c|c|c|c|c|c|c|c|c}
\hline 决策单元 & $\theta^{*}$ & - & - & - & - & - & - & - & - & - \\
\hline
\end{tabular}




\begin{tabular}{l|l|l|l|l|l|l|l|l|l|l}
\hline 2015 (DMU4) & 1 & 0 & 0 & 0 & 0 & 0 & 0 & 0 & 0 & 0 \\
\hline 2016 (DMU5) & 1 & 0 & 0 & 0 & 0 & 0 & 0 & 0 & 0 & 0 \\
\hline 2017 (DMU6) & 1 & 0 & 0 & 0 & 0 & 0 & 0 & 0 & 0 & 0 \\
\hline 2018 (DMU7) & 1 & 0 & 0 & 0 & 0 & 0 & 0 & 0 & 0 & 0 \\
\hline 2019 (DMU8) & 1 & 0 & 0 & 0 & 0 & 0 & 0 & 0 & 0 & 0 \\
\hline
\end{tabular}

\begin{tabular}{|c|c|c|c|c|c|c|}
\hline 决策单元 & $\theta^{*}$ & $\stackrel{+}{S_{1}} *$ & $\stackrel{+}{S_{2}} *$ & $\begin{array}{l}+ \\
S_{3}\end{array}$ & $\stackrel{+}{S 4} *$ & $\begin{array}{l}+ \\
S 5\end{array}$ \\
\hline 2012 (DMU1) & 10.1 & 0 & 0 & 0 & 0 & 0 \\
\hline 2013 (DMU2) & 10.4 & 0 & 0 & 0 & 0 & 0 \\
\hline 2014 (DMU3) & 11.4 & 0 & 0 & 0 & 0 & 0 \\
\hline 2015 (DMU4) & 11.9 & 0 & 0 & 0 & 0 & 0 \\
\hline 2016 (DMU5) & 10.1 & 0 & 0 & 0 & 0 & 0 \\
\hline 2017 (DMU6) & 9.2 & 0 & 0 & 0 & 0 & 0 \\
\hline 2018 (DMU7) & 10.4 & 0 & 0 & 0 & 0 & 0 \\
\hline 2019 (DMU8) & 9.2 & 0 & 0 & 0 & 0 & 0 \\
\hline
\end{tabular}

\subsection{Malmquist DEA 分析}

\subsection{1. 模型的设立}

Malmquist 在 1978 年提出技术进步（tfpch）可 以分解为生产效率的变化 (effch) 和技术的变化 （techch），即技术进步的变化 tfpch 等于生产效率的 变化 effch 乘以技术的变化 techch, 因而使用 Malmquist DEA 分析方法可以清晰地看到民间投资为 各个行业的发展所带来的技术进步的具体变化。技术 进步的变化 $\mathrm{tfpch}$ 是一个指数, 将该指数与 1 进行比 较, 当某个决策单元的 $\mathrm{tfpch}$ 大于 1 时, 说明该决策 单元的综合效率值和技术值的变化都是正的, 也就是 说该决策单元的效率是优的。由于综合效率 (effch) 等于规模效率（sech）乘以纯技术效率（pech），因 而, 上述技术进步的变化公式可以写成: tfpch $=$ sech $\times$ pech $\times$ techch.

对于 17 个行业的 Malmquist DEA 分析, 我们选 择各个行业的行业增加值作为输出变量, 投向各个行 业的民间资本数量作为输入变量, 研究阶段为 20122019 年。

\subsection{2. 模型求解及分析}

将 2012-2019 年我国 17 个行业的行业增加值和 行业民间投资数据代入 DEA 模型中, 使用产出角度 的 Malmquist DEA 分析方法, 可以得出我国 17 个行 业的技术进步指数、综合效率值、技术变化值、纯技 术效率值和规模效率值, 如表 2 所示。序列 1-17 分 别代表农林牧渔业, 采矿业, 制造业, 电力、燃气及 水的生产和供应业, 建筑业, 交通运输、仓储和邮政 业, 批发和零售业, 住宿和餐饮业, 金融业, 房地产, 科学研究、技术服务和勘探业, 水利、环境和公共设
施管理，居民服务和其他服务业，教育，卫生、社会 保障和社会福利业，文化、体育和娱乐业以及公共管 理和社会组织。

根据模型求解的结果（表 2)，我们可以看到, 第一个单元为农林牧渔业, 该行业的综合效率值是 0.842 (小于 1 ), 说明农林牧渔效率变化呈下降趋势。 以此类推, 我们可以看到, 从生产效率来说, 建筑业, 房地产业, 教育以及公共管理和社会组织这四个行业 的效效率处于优秀状态; 金融业的年均生产效率保持 不变; 其他行业的生产效率都是下降的, 其中, 批发 和零售业的生产效率值是 0.995 , 接近 1 , 相对来说, 批发和零售业的生产效率变化是比较优的。从纯技术 效率来看, 除了电力、率值均大于 1 , 说明这四个行 业的年均生产效率值是上升的，民间投资在这四个行 业的生产业的年总体效率平均值是下降的, 其技术变 化指数 0.879 也小于 1 , 说明农林牧渔业在八年间的 技术效率变化也是下降的, 纯技术效率值为 1 表明农 林牧渔业的纯技术效率是不变的, 规模效率指数是 0.842 , 即农林牧渔业的规模燃气及水的生产和供应 业, 科学研究、技术服务和勘探业, 居民服务和其他 服务业，卫生、社会保障和社会福利业以及文化、体 育和娱乐业这五个行业的纯技术效率是下降的, 其他 12 个行业的纯技术效率都是上升的, 而且处于下降趋 势的五个行业的纯技术效率指数均在 0.95 以上, 较 为接近 1 , 因此, 根据综合效率等于纯技术效率乘以 规模效率的原理, 我们可以推测, 大部门行业的规模 效率都是下降的, 而从得到的规模效率分析结果来看, 只有金融业和房地产业这两个行业的规模效率指数 不小于 1 。因此, 要提高民间投资在各个行业的生产 效率, 除了提高部门行业的纯技术效率外, 重点要提 高民间投资在各行业发展中的规模效率。技术进步是 第一生产力, 而模型求解的结果表明, 我国民间投资 在各行业中的技术进步指数值都是小于 1 的, 技术进 
步的年均变化处于下降趋势, 只有房地产业、教育以 及公共管理和社会组织这三个行业的指数值大于 0.9 , 民间投资效率处于相对较优的状态。技术进步的变化 可以分解为生产效率的变化和技术效率的变化, 从技
术效率变化来看, 17 个行业的技术效率变化都处于下 降趋势，因此，要想提高民间投资的行业结构效率, 除了提高民间投资在各行业发展中的综合效率，还必 须提高民间投资在各行业发展中的技术水平。

\section{表 $22012-2019$ 年我国民间投资行业 结构效率 Malmquist DEA 分析结果}

\begin{tabular}{|c|c|c|c|c|c|}
\hline firm & Effch & Techch & Pech & Sech & Tfpch \\
\hline 1 & 0.842 & 0.879 & 1 & 0.842 & 0.74 \\
\hline 2 & 0.874 & 0.879 & 1.055 & 0.828 & 0.768 \\
\hline 3 & 0.89 & 0.879 & 1 & 0.89 & 0.782 \\
\hline 4 & 0.95 & 0.879 & 0.988 & 0.961 & 0.835 \\
\hline 5 & 1.014 & 0.879 & 1.119 & 0.906 & 0.891 \\
\hline 6 & 0.878 & 0.879 & 1.013 & 0.866 & 0.771 \\
\hline 7 & 0.995 & 0.879 & 1.08 & 0.921 & 0.874 \\
\hline 8 & 0.89 & 0.879 & 1.027 & 0.867 & 0.782 \\
\hline 9 & 1 & 0.879 & 1 & 1 & 0.879 \\
\hline 10 & 1.083 & 0.879 & 1.074 & 1.008 & 0.952 \\
\hline 11 & 0.909 & 0.879 & 0.993 & 0.915 & 0.799 \\
\hline 12 & 0.886 & 0.879 & 1.03 & 0.86 & 0.778 \\
\hline 13 & 0.922 & 0.879 & 0.988 & 0.933 & 0.81 \\
\hline 14 & 1.08 & 0.879 & 1.123 & 0.963 & 0.949 \\
\hline 15 & 0.919 & 0.879 & 0.959 & 0.959 & 0.808 \\
\hline 16 & 0.85 & 0.879 & 0.981 & 0.866 & 0.747 \\
\hline 17 & 1.054 & 0.879 & 1.114 & 0.946 & 0.926 \\
\hline mean & 0.94 & 0.879 & 1.031 & 0.912 & 0.826 \\
\hline & & & & & \\
\hline
\end{tabular}

\section{表 3 我国民间投资行业结构效率的年度变化}

\begin{tabular}{|l|l|l|l|l|l|}
\hline & effch & techch & pech & sech & tfpch \\
\hline 2 & 1.119 & 0.607 & 1.034 & 1.082 & 0.68 \\
\hline 3 & 0.69 & 1.206 & 1.036 & 0.666 & 0.832 \\
\hline 4 & 0.879 & 1.078 & 1.048 & 0.838 & 0.947 \\
\hline 5 & 1 & 0.831 & 1.031 & 0.969 & 0.831 \\
\hline 6 & 0.943 & 0.829 & 1.028 & 0.917 & 0.782 \\
\hline 7 & 1.081 & 0.846 & 1.008 & 1.072 & 0.914 \\
\hline mean & 0.94 & 0.879 & 1.031 & 0.912 & 0.826 \\
\hline
\end{tabular}

表 3 是八年间民间投资行业结构效率的变化趋 势, 从表中结果我们可以看到, 随着时间的推移，民 间投资的行业结构效率在总体上是提升的, 但发展过 程具有起伏性。具体来说，民间投资的纯技术效率一 直处于相对稳定的状态, 规模效率时起时落, 从而使 得综合效率的发展也出现一定的起伏。技术效率的变 化仅在第三、第四年时表现较优, 之后则出现回落

\section{5. 结论}

综合以上分析，我国民间投资行业结构存在一定 的不合理性，而且民间投资的行业结构效率普遍较低。 虽然民间投资投向制造业和房地产业的数量最多，但 是, 这两个行业的效率值表现并不是特别突出, 尤其 是制造业，其效率值基本上都小于 1 。民间资本投在
垄断性、科技含量高的行业数量仍然非常微小。因此, 提高民间投资的行业结构效率，不仅要放宽民间投资 的进入领域，更重要的是提高民间投资的利用效率， 特别是民间投资的技术效率。

\section{REFERENCES}

[1] Sheng Zhaohan, Zhu Qiao, Wu Guangmou (1996) ,DEA theory, method and application, Science Press, Beijing.

[2] A.CharnesW.W.Cooper,E.Rhodes.Measuring the Effieieney of Deeision Making Units[J].European Journal of Operational Research, 1978, 6(2):429444. 
[3] Zhou Zejiong,Ye Zuoya, Research on the Evaluation of Private Investment Efficiency and the Countermeasures, Journal of Changchun Normal University, vol.39, pp. 42-47, 2020

[4] Qiu Xinfeng,Zhao Kunting, China's private investment policy evolution, economic performance and long-term mechanism construction in the past 40 years of reform and opening up, Business economy, pp.64-73,2018

[5] Yu Xue, Factor allocation, government boundary and macro-investment efficiency, Shanghai Finance, pp.26-31,2019 